\title{
The Social Cost of Uniform Regulatory Standards in a Hierarchical Government
}

\author{
CAROL AdAire Jones \\ University of Michigan, Ann Arbor, Michigan 48109 and Resources for the Future, \\ 1616 P St. NW Washington, D.C. 20036 \\ AND \\ SuZANne SCOTCHMER \\ University of California, Berkeley, California 94720 \\ Received August 11, 1988; revised March 20, 1989

\begin{abstract}
Regulatory agencies charged with public health and safety typically promulgate uniform regulatory standards, which suggests the agencies are concerned mainly to reduce harmful externalities, with little concern for firms' costs. A focus on benefits, to the exclusion of costs, in standard-setting and enforcement leads to inefficiencies. We show that, even when the legislature cannot peg the budget to a specific enforcement policy, it can reduce the distortions by limiting the enforcement agency's budget and by permitting the agency to partially self-finance from rebates of noncompliance fines. 1990 Academic Press, Inc.
\end{abstract}

The large-scale expansion of federal health and safety regulation was a major political development in the late $1960 \mathrm{~s}$ and the 1970s. Alliances between the growing numbers of liberal Democrats in Congress and advocates for environmental and workplace safety spurred Congress to pass strong protective legislation without regard to the costs of protection. ${ }^{1}$ A newly activist judiciary has compelled the new regulatory agencies to comply with the protective language. ${ }^{2}$ For example, the courts have explicitly ruled out the use of cost-benefit considerations in several legal challenges to standards set by the Environmental Protection Agency [EPA] and the Occupational Safety and Health Administration [OSHA]. ${ }^{3}$

${ }^{1}$ For example, the Occupational Safety and Health Administration (OSHA) statute directs the agency to implement standards which attain the "highest degree of health and safety protection for the employee" [section 6(b)(5)]. The Environmental Protection Agency (EPA) is mandated to set standards incorporating "an adequate margin of safety" for all pollutants that "endanger the public health or welfare," (section 108). Between 1968 and 1978, Congress promulgated a wide range of "new" social legislation employing similar regulatory strategies, including the Consumer Product Safety Act, Traffic Safety Act, Child Protection and Toy Safety Act, Coal Mine Health and Safety Act, Surface Mining Control and Reclamation Act, Truth-in-Lending Act, and Toxic Substance Control Act, among others.

${ }^{2}$ See Melnick [11] for a discussion of the new form of interest group partnerships among courts, regulatory agencies, and Congressional legislative subcommittees that developed in the 1970 s to promote protective regulation.

${ }^{3}$ The use of economic efficiency principles has been extensively litigated in OSHA and EPA standard-setting. For example, in Chevron v. NRDC 52 U.S.L.W. 4845 (1984), the DC Circuit prohibited the agency from considering the cost of alternative air pollution standards, based on language in the 1970 Senate report and the 1977 House report. When the Court vacated the OSHA benzene standard, it directed the agency to find "significant risk," a benefit-based concept, before promulgating standards. (Industrial Union Department v. American Petroleum Institute, 448 US 607 (1980).) In the cotton dust decision, the Court explicitly rejected the use of cost-benefit analysis in the development of OSHA health standards. (American Textile Manufacturers Institute v. Donovan, 452 US 490 (1981).) 
In this new political climate, agencies charged with public safety typically have chosen uniform standards: all firms must comply, regardless of the cost of compliance. The uniform standards are widely criticized as inefficient, on the grounds that efficient standards would apply only to firms for which the social benefit exceeds the social cost of compliance. ${ }^{4}$ However, the criticism of uniform standards is potentially shortsighted because it fails to distinguish between the stipulated standards and the effective standards represented by the pattern of compliance induced by enforcement. Firms will self-select to comply with the standard only if the cost of compliance is less than the expected fine for non-compliance. The pattern of compliance that emerges will depend on the agency's enforcement goal and on its enforcement budget. Because most legislative statutes establish fine ceilings, ${ }^{5}$ reductions in the enforcement budget will reduce compliance.

We consider an extreme scenario in which the agency's enforcement goal reflects the protective language in the statute: we assume that the agency maximizes the public benefits of compliance, with a zero weight on the firms' costs of compliance. However, the enforcement budget is set by the Congressional appropriations committees. Appropriations committees generally represent broader interests than the legislative committees, which tend to attract advocates for the program areas in which they write legislation. Consequently, one plausible mechanism for the firms bearing the costs of regulation to influence regulatory outcomes is to influence the enforcement budget chosen by the appropriations committees. ${ }^{6}$

Following this logic, we examine the case in which the goal of the appropriations committees in budget-setting is to maximize the gross benefits of compliance net of firms' compliance costs and agency enforcement costs. We investigate the power of the appropriations committees to reduce the inefficiencies of agencies that focus solely on the gross benefits of compliance. Appropriations committees wield two budget instruments: they can set budgets, and can (possibly) set a rebate policy in which the agency keeps a share of the fine revenue it collects. We assume that the budget cannot be pegged to a specific enforcement policy, such as efficiently balancing firms' private costs against public benefits, because efforts to circumvent the protective legislative goals during enforcement could be challenged in court or in oversight committees, as has occurred with standard-setting.

Enforcement agencies typically have some information, but not perfect information, about firms' costs of compliance. Such information can help agencies target their enforcement and can potentially reduce the cost of achieving any stipulated level of compliance. However, such information can also exacerbate the distortions that result when the agency cares only about the benefits of compliance and not about firms' costs. We show how the power of the budget instruments is affected by the type of information available to the agency.

Our model of government is hierarchical: The appropriations committees constrain the agency through its budget and the agency disciplines firms with inspections and fines. We show that in some circumstances, the pattern of compliance can be made very similar to the pattern of compliance that maximizes benefits of

\footnotetext{
${ }^{4}$ See, for example, Kneese and Bower [9], Kneese and Schultze [10] Nichols and Zeckhauser [13] Nichols [12], and the wide-ranging U.S. Senate Study on Federal Regulations [18].

${ }^{5}$ Jones [7] summarizes the enabling legislation that sets various enforcement agencies' fine rates.

${ }^{6}$ See Fenno [5] and Schick [15] for discussions of the various committees involved in the budget process.
} 
compliance net of firm's compliance costs and agency enforcement costs, even if the agency's objective is to maximize the gross benefits of compliance without explicit regard for firms' compliance costs. We also show that the pattern of compliance across firms with different compliance costs will be more efficient if the agency must partially finance its inspections from fines.

Section 1 illustrates the distortions in the enforcement policy when the agency maximizes gross benefits of compliance rather than net benefits of compliance. Section 2 shows how the precision of a signal of firms' costs affects the allocative distortion. Section 3 demonstrates how distortions are generally reduced by partial financing through fine rebates and exacerbated when prosecution of violators is costly. Section 4 concludes the paper.

\section{DISTORTIONS IN ENFORCEMENT POLICY WITH AN INEFFICIENT AGENCY}

We assume that firms have different unobservable costs, $g$, for complying with the regulation. ${ }^{7}$ However, each firm has an observable cost signal, $y$, such as its industry or product line, which is correlated with its compliance cost. For simplicity, we assume that the signal equals the mean of the cost distribution $E(g \mid y)=y .^{8}$ Since the signal is observable before inspection, the enforcement agency can choose a different frequency of inspection for each cost signal, $y$. The cost of an inspection is $c$ and the fine imposed on a noncompliant firm is $f$. We assume the allowable fine is fixed and not chosen as part of the enforcement policy.

We assume that compliance costs in class $y$ are distributed symmetrically around $y$ according to $H(g-y)$, on a support contained in $(y-m, y+m)$. Thus, each inspection class has the same distribution of costs, except for location, $y$. For each $y, H$ is differentiable and positive on the interior of its support.

If a firm in class $y$ is inspected with probability $p(y)$, it will self-select to comply if $g<p(y) f$, and therefore the compliance rate in inspection class $y$ will be $H(p(y) f-y)$. This self-selection by cost is why the pattern of compliance can be close to efficient even if the agency does not care directly about firms' costs. There is no analogous mechanism to make them self-select by benefits, but if the agency wants to maximize benefits of compliance, it will set higher expected fines in sectors where the benefits of compliance are high. Since our arguments would be neither enriched nor undermined by assuming that the benefits of compliance differ across firms, we assume the social benefit of each firm's compliance is one. Aggregate benefits are $\sum_{y} H(p(y) f-y)$. (With little loss of generality and no loss of insight, we assume that all inspection classes are the same size.)

\footnotetext{
${ }^{7}$ For simplicity, we study regulations that are "either/or": Either an automobile in California has an emissions control device, or it does not. Either a coal-burning electricity plant installs smoke scrubbers or it does not. While a model with variable compliance levels would be richer, this simple model allows us to make our main points.

${ }^{8} \mathrm{We}$ assume the signal is costless to observe. Public sources of cost information include the U.S. Census Bureau data on the costs of different regulations at the 4-digit SIC level, based on an annual survey of 20,000 firms. See Evans [4] for summary statistics. Also, the agencies generally have spent substantial sums of money to collect regulatory cost data during the rule-making process. See, for example, Research Triangle Institute, "Regulatory Analysis of the Proposed OSHA Standards on Asbestos," prepared for OSHA, U.S.D.O.L., May 1984 [14].
} 


\section{A. The Enforcement Policy that Maximizes Net Benefits of Compliance}

We first characterize the inspection probabilities $p^{*}(y)$ that maximize the net benefits of compliance with the fine rate fixed. In class $y, G^{*}(y)=p^{*}(y) f$ separates compliant from noncompliant firms. $G^{*}(y)$ maximizes social welfare $S W$, conditional upon fixed fines:

$$
S W(G, y)=H(G-y)-\int_{y-m}^{G} g h(g-y) d g-c G / f
$$

We shall refer to $G^{*}(y)$ as the efficient pattern of compliance. The first term in (1) is the benefit of compliance, the second term is the compliance cost borne by firms, and the third term is the cost of inspections. If inspection class $y$ is inspected at all, the first-order condition describing the optimal $G^{*}(y)$ or, equivalently, the optimal $p^{*}(y)$, is

$$
[1-G]-c /[f h(G-y)] \geq 0, \quad \text { with equality if } H(G-y)<1 .
$$

We can differentiate (2) implicitly to see how the compliance rate optimally changes with the cost signal within inspected classes. Assuming the objective function is strictly concave at the optimum, and $0<H\left(G^{*}(y)-y\right)<1$, it follows that $d G^{*}(y) / d y<1$. Since $d G^{*}(y) / d y<1$, the compliance rate declines with $y: \mathrm{A}$ high-cost class has a lower compliance rate than a low-cost class at the social optimum.

High-cost inspection classes should not be inspected at all if the costs outweigh the benefits for all inspection probabilities. ${ }^{9}$ There is a "cutoff" cost signal, say $Y^{*}$, above which inspection classes should escape scrutiny.

\section{B. The Enforcement Policy that Maximizes Compliance}

We now investigate the pattern of compliance that is induced when the agency chooses its enforcement policy to maximize benefits of compliance subject to an enforcement budget, $E$, set by the appropriations committee. The enforcement agency chooses $G(y, E)$ (for each $y$ ) to maximize

$$
\sum_{y} H(G(y, E)-y) \quad \text { subject to } E=c \sum_{y}[G(y, E) / f] .
$$

Here we have again substituted $G / f$ for $p$. Provided a class is inspected, the first-order condition describing the optimum is

$$
\begin{aligned}
{[1 / v(E)]-c /[f h(G(y, E)-y)] } & \geq 0, \\
\text { with equality if } H(G(y, E)-y) & <1,
\end{aligned}
$$

\footnotetext{
${ }^{9}$ If the regulation applies to a prominent industry, selective nonenforcement may be politically untenable. For example, the corporate average fuel economy (cafe) standard applies to the automobile industry, which has three very large domestic participants. The costs of compliance vary substantially across the firms, but it is generally considered to be politically infeasible to enforce the standard selectively within the industry. The result, however, has not been full compliance. The industry is engaged in negotiations with the government to revise the standard.
} 
where $v(E)$ is the shadow value of an additional dollar in producing compliance. Since the agency does not take into account firms' private compliance costs, the marginal benefit perceived by the agency of increasing the compliance by one firm is one. The marginal benefit $1 / v(E)$ is the dollar value of marginal compliance, given that the budget is constrained.

Within inspected classes, the compliance rate will be uniform. It may be too high in high-cost classes but too low in low-cost classes or it may be uniformly too high in inspected classes relative to the efficient pattern of compliance described above.

An important feature of both inspection patterns $G^{*}(y)$ and $G(y, E)$ is that some high-cost (high $y$ ) inspection classes may not be inspected at all, though the cutoff may be different in the two cases. It takes a higher frequency of inspection to elicit a given compliance rate from a high-cost inspection class than from a low-cost inspection class. Eliciting compliance from firms in a high-cost inspection class may cost more than its value to the enforcement agency with either enforcement goal. Though the agency does not care directly about private costs of compliance, it nevertheless exempts high-cost inspection classes because the budget is limited and inducing compliance from high-cost firms is costly.

The agency seeking to maximize compliance will consider itself underfinanced, since it could increase compliance if it had a higher budget.

\section{THE POWER OF BUDGET INSTRUMENTS, I: THE LEVEL OF THE BUDGET}

To evaluate the severity of the efficiency distortions when the enforcement agency maximizes aggregate compliance, rather than compliance net of firms' costs, it is instructive to consider the two extreme cases, (i) the cost signal is totally informative and (ii) there is no cost signal. With no cost signal, the enforcement agency can observe nothing prior to inspection and will inspect firms with the same probability, with both enforcement goals, provided the appropriations committees provide the same budget in both cases. There will be a uniform "cutoff" cost level below which firms comply.

At the other extreme, if $y$ is a perfect signal of cost, all firms with signal $y$ have the same cost $g=y$. The probabilities of inspection will be $p(y, E)=y / f$ for $y$ less than the cutoff determined by the enforcement agency's budget. Therefore, with the same budget, the agency will achieve the same pattern of compliance whether it maximizes the benefits of compliance or the net benefits of compliance. As a preliminary result, we record this as a proposition:

Proposition 1. When (i) no cost signal is available, or (ii) the cost signal is perfectly correlated with compliance cost, the appropriations commiltees can achieve the same compliance patterns from an agency that maximizes the gross benefits of compliance as they could achieve from an agency that maximizes the benefits of compliance net of firms' costs.

Except in the two extreme cases mentioned, this equivalence in the patterns of compliance does not hold. It is therefore of interest to ask whether the social loss with the distorted agency goal inevitably becomes small as the extremes are approached. 
We say that cost signals become more informative if the distribution of compliance costs, $H$, becomes more compressed around the mean, but the distribution of signals $y$ is fixed. ${ }^{10}$ Hence, the distributions of compliance cost in different classes overlap less as the signal becomes more informative. We index a sequence of distributions by $n=1,2, \ldots$, and let $H^{n}(g-y)=H(n(g-y))$. The support of $H^{n}$ is contained in $[y-(m / n), y+(m / n)]$ and the density, $h^{n}(g-y)=$ $n h(n(g-y))$, becomes arbitrarily large on the interior of the support, where $h$ is positive.

We showed in the extended version of this paper [8] that as the density $h^{n}$ becomes very large everywhere on the interior of its support, the compliance rates in inspected classes approach one, both when the agency maximizes the benefits of compliance and when it maximizes the benefits of compliance net of firms' costs. In each case, the intuition is that a small increase in the probability of audit would otherwise generate a huge increase in compliance. Furthermore, by awarding the same budget in each case, the appropriations committees can ensure that the high-cost inspection classes that escape scrutiny when the agency maximizes the gross benefits of compliance are almost the same as those that would escape scrutiny if the agency maximized the net benefits of compliance. Therefore:

PROPOSITION 2. As the distribution of compliance cost in each class becomes more concentrated around its mean $y$ ( $n$ becomes large), the social loss due to the fact that the agency maximizes the benefits of compliance, rather than the net benefits of compliance, converges to zero.

At the other extreme, we say that cost signals become less informative if the distribution of signals $y$ becomes more compressed around its mean, while the distribution of compliance costs, $H$, remains fixed within each compliance class. ${ }^{11}$ Hence, the distributions of compliance cost in different classes overlap more as the signal becomes less informative.

Unfortunately, it is not always true that the social loss becomes small as the distribution of signals $y$ becomes concentrated at its mean. A condition under which the social loss does become small is that the compliance-cost density $h$ is strictly declining at the efficient inspection rate. This condition is violated when $h$ is uniform and, if the efficient compliance cutoff is less than the mean, when it is normal. Large inefficiencies may result, as the following example shows.

EXAmple. Consider a case with two classes, $y_{1}$ and $y_{2}$, in which compliance costs are uniformly distributed. If the enforcement agency inspects an inspection class at all, it elicits full compliance from that inspection class. ${ }^{12}$ (In (4), $h$ is constant.) As the distributions of compliance cost become very close (as one signal becomes close to the other), this pattern persists. As a result, a large social loss persists because high-cost firms in the low-signal class will comply, but low-cost firms in the high-signal class will not comply.

The interpretation of this example is that a little information might be a bad thing. If the mean compliance costs in two industrics differ only slightly, the

\footnotetext{
${ }^{10}$ For example, if $h(g-y)=(n / 2 m)$ on the support $(y-(m / n), y+(m / n))$, the cost signal becomes more informative if $n$ becomes larger. The distribution of signals remains fixed.

${ }^{11}$ For example, if there are only two signals, $y_{1}$ and $y_{2}$, the case cost signals become less informative as these two signals move toward their mean, $y_{m}=(1 / 2)\left(y_{1}+y_{2}\right)$.

${ }^{12}$ The one possible exception is the highest-cost inspection class it inspects: the agency may run out of budget before it can induce full compliance from this class.
} 
enforcement agency may enforce one of them heavily and the other not at all, which may be very far from optimal. It is unclear whether appropriations committees have the power to prevent agencies from using their cost information. For completeness, we point out the relevant considerations if they do have this power.

The example shows that ordering the agency to ignore the cost signals could save social costs by reducing firms' private compliance costs for a given compliance rate. Whether such a policy would be optimal depends on whether this cost saving outweighs the higher inspection costs that are required to achieve any specified level of compliance when there is no cost information. If cost information is good, in the sense that the distributions of compliance costs in different inspection classes do not overlap much, the agency should be permitted to use its information. On the other hand, if cost information is imprecise in the sense that the distributions of firms' compliance costs are nearly indistinguishable across different inspection classes, then it may or may not serve the public interest to order the inspection agency to ignore the cost signal.

The right decision depends on details of the density function of compliance costs. Assuming that the appropriations committee cannot decide on a case-by-case basis, perhaps a reasonable policy is always to prevent the agency from using cost information if the information is imprecise in the above sense. With a given budget, the agency's preferred pattern of compliance without using the cost signal is close to the efficient pattern of compliance with the imprecise cost signal. Any social loss from mistakenly not using the cost signal is therefore low. And the savings from reducing firms' private compliance costs may be large in the type of situation described by the example, in which using the cost signal results in overenforcement of some high-cost firms, but underenforcement of some low-cost firms.

\section{THE POWER OF BUDGET INSTRUMENTS, II: REBATED FINE REVENUES}

We now consider how the pattern of compliance achieved by the compliancemaximizing enforcement agency is affected when the agency is required partially to self-finance by retaining a share of the fines it collects. The rebate mechanism we have in mind is an implicit understanding between the appropriations committee and the agency that last year's fine revenues will be considered in this year's budget. The more direct mechanism of off-line budgeting also exists, though it appears to be rarely used for noncompliance penalties received from violators. ${ }^{13}$

With probability $1-H(\cdot)$, an inspected firm is noncompliant, and will be prosecuted and fined. Suppose the appropriations committees permit the agency to keep a fraction $r$ of the fine revenues to finance other inspections. We can substitute $G(y, E, r) / f$ for $p(y, E, r)$ to describe the enforcement agency's objective function. For each $y$, the enforcement agency chooses $G(y, E, r)$ to solve:

$$
\begin{array}{r}
\operatorname{Maximize} \sum_{y} H(G(y, E, r)-y) \quad \text { subject to } \quad E=\sum_{y} c[G(y, E, r) / f] \\
-r f \sum_{y}[G(y, E, r) / f][1-H(G(y, E, r)-y)] .
\end{array}
$$

\footnotetext{
${ }^{13}$ See U.S.G.A.O., $1987[17]$.
} 
If compliance in class $y$ is positive, the first-order condition describing the optimum is

$$
\frac{1}{v(E, r)}-\frac{c}{f h(\cdot)}+\frac{r[1-H(\cdot)]}{h(\cdot)}-r G(\cdot) \geq 0
$$

where, again, $v(E, r)$ is the shadow value of an enforcement dollar in producing compliance. The condition holds with equality if the compliance rate in class $y$ is less than one, and with inequality if all firms in class $y$ comply.

When there are no fine rebates, the marginal cost of inspections, $c /[f h(\cdot)]$, is the same in each inspection class at each compliance level $H(\cdot)$. But with rebates, the marginal cost curves in different inspection classes differ because the values of fine rebates differ. With equal compliance rates, $H$, there are more inspections in a high-cost class than in a low-cost class, since it takes a higher probability of inspection to make the same fraction of higher-cost firms comply. When the compliance rate $H$ increases at the margin, rebates are lost on more inframarginal inspections in a high-cost class than in a low-cost class, and this makes the agency's effective marginal cost of inspections higher in the high-cost sector.

PROPOSITION 3. The best budget policy when the enforcement agency maximizes the gross benefits of compliance, rather than the net benefits, requires rebates as well as direct budget, since rebates encourage the agency to shift inspections from high-cost classes to low-cost classes.

Proof. There are many combinations of rebates $r$ and direct budgets $E(r)$ that induce the same fixed total expenditure on inspections, say $E^{*}$. Starting with no rebates, $r=0$, and the direct budget $E(0)=E^{*}$, we will show that a marginal increase in $r$ [and the corresponding decrease in $E(r)$ required to hold expenditures on enforcement fixed] increases social welfare. We will simplify notation by writing $G(y, r)$ and $v(r)$ instead of $G(y, E(r), r)$ and $v(E(r), r)$.

Since total expenditures on inspections are fixed at $c \sum_{y} p(y)=(c / f) \Sigma_{y} G(y, r)$, constant total expenditures imply that $\Sigma_{y}[\partial G(\cdot) / \partial r]=0$. Social welfare is

$$
S W=\sum_{y} \int_{y-m}^{G(y, r)}(1-g) h(g-y) d g-(c / f) \sum_{y} G(y, r) .
$$

Since the derivative of the last term with respect to $r$ is zero, the change in social welfare when $r$ increases marginally is the derivative of the first term, or

$$
\partial S W / \partial r=\sum_{y}[1-G(y, r)] h(G(y, r)-y)[\partial G(y, r) / \partial r]
$$

We will evaluate the derivative at the initial point, $r=0$. Since the agency choice of $G(y, 0)-y$ is constant for all $y$ (from Eq. (4) above), $h(G(y, 0)-y$ ) has the same value, say $h$, for all $y$ for which $0<H(\cdot)<1$. Therefore the derivative of social welfare at $r=0$ has the value

$$
h \sum_{y}[\partial G(y, 0) / \partial r]-h \sum_{y} G(y, 0)[\partial G(y, 0) / \partial r] .
$$


Since the first term is zero, we only need to show that the last term is positive. Differentiating (6) implicitly and then setting $r=0$, we discover that, for inspection classes with positive compliance, but not full compliance,

$$
\begin{aligned}
\frac{\partial G(y, 0)}{\partial r}= & \frac{f h(G(y, 0)-y)}{c h^{\prime}(G(y, 0)-y)} \\
& \times\left\{\frac{h(G(y, 0)-y)}{v(0)^{2}} \frac{d v(0)}{d r}\right. \\
& \quad-[1-H(G(y, 0)-y)-h(G(y, 0)-y) G(y, 0)]\}
\end{aligned}
$$

The second-order condition for (3) (or (5) at $r=0$ ) requires $h^{\prime}(\cdot) \leq 0$. For the following reason, it will not be cost-effective for the agency to have $h^{\prime}(\cdot)=0$. By symmetry and single-peakedness of $h, h^{\prime}(\cdot)=0$ would imply the compliance rate was $50 \%$ in all inspected classes. Consider any two such classes. By symmetry of $h$, the cost-savings of decreasing compliance in one class to zero is the same as the additional cost of increasing compliance in the other class to one, and the same aggregate compliance is preserved. But now there is an additional lump-sum cost saving in the sector whose compliance rate has been reduced to zero, since it takes a nontrivial inspection cost $(y-m) / f)$ to achieve the lowest-cost firms' compliance in that class. This lump-sum saving means that the compliance rates zero and one are less costly to achieve than compliance rate $50 \%$ in both sectors, and therefore the gross-benefits optimum will not have $h^{\prime}(\cdot)=0$.

Since $h(\cdot), h^{\prime}(\cdot)$ and $H(\cdot)$ respectively have the same values for all $y$ when $r=0$, and since $h^{\prime}(\cdot)<0$ by the second order condition, we see that $\partial G(y, 0) / \partial r$ $=a-b G(y, 0)$ for appropriate constants $a$ and $b>0$. Given that $\partial G(y, 0) / \partial r$ decreases with $y$, that $\Sigma_{y} \partial G(y, 0) / \partial r=0$, and that $G(y, 0)$ increases with $y$, it must be that $\Sigma_{y} G(y, 0) \partial G(y, 0) / \partial r<0$. In multiplying $\partial G(y, 0) / \partial r$ by $G(y, 0)$, we are weighting the negative values of $\partial G(y, 0) / \partial r$ more heavily than the positive values. It follows that $-\sum_{y} G(y, 0)[\partial G(y, 0) / \partial r] \geq 0$.

Thus, within the inspection classes with positive but not complete compliance, social welfare increases with a marginal increase in $r$, from $r=0$. There will be no change in compliance of the inspection classes for which compliance is zero. The marginal adjustment to $r$ could generate at most a marginal saving in enforcement costs to be applied to inspection classes with no compliance. The smallest probability of inspection that will elicit positive compliance from such an inspection class is $c(y-m) / f$, which is nonmarginal.

Q.E.D.

\section{Prosecution Costs}

If the enforcement agency maximizes social welfare rather than aggregate compliance, there is no social loss due to the uniform standard when fine rates are fixed. The effective regulatory standard, after enforcement, would be the efficient nonuniform standard. This result does not hold if prosecuting noncompliant firms is costly. Suppose the enforcement agency incurs prosecution costs, $e$, to document or litigate noncompliance. If the regulatory standard could be nonuniform, an agency operating in the public interest could avoid prosecution costs (without changing incentives 
to comply) by stipulating that any firm with compliance cost greater than $G^{*}(y)=$ $p^{*}(y) f$ is exempt. Since the only noncompliant inspected firms would be exempt from compliance, no firms would be prosecuted and the costs would be avoided. But with a uniform standard, prosecution costs generally cannot be avoided when noncompliant firms are detected in inspected sectors.

For the enforcement agency that maximizes gross benefits of compliance, the de jure obligation to prosecute firms detected to be noncompliant exacerbates the inefficient distribution of compliance among inspected classes. The enforcement problem with costly prosecution can again be described by (5), except that we must substitute $+e$ for $-r f$. Instead of getting a rebate $r f$ for every noncompliant firm it inspects, the enforcement agency pays a prosecution cost, $e$. The incentives due to rebated fines are then reversed. Prosecution costs inefficiently shift inspections from low-cost inspection classes to high-cost inspection classes. Though the result may appear initially surprising, the intuition is analogous to the rebate case above: Frequent inspections of high-cost classes increase compliance, thereby decreasing the expected prosecution costs. As compliance increases, the reduction in prosecution costs is greater in high cost sectors because they require far more inspections to achieve a given compliance rate.

\section{CONCLUSIONS}

This paper is motivated by the widespread criticism of uniform regulatory standards, which holds that efficient standards would apply only to firms for which the social benefit exceeds the social cost of compliance. We have argued that this criticism may be overstated, since the inefficiencies in uniform standards can be reduced through the exercise of power over the agency's enforcement budget. We assume that when regulatory agencies set uniform standards, they also enforce the standards in a way that places more weight on the benefits of compliance than firms' private compliance costs. If such an agency could choose its own budget or the fine rate, it would be overinclusive in its enforcement efforts, relative to the efficient level of enforcement. By restricting the agency budget, the Congressional appropriations committees can induce the agency to avoid inspecting the higher cost inspection classes for which compliance is inefficient. If the agency has a good signal of firms' unobserved compliance costs, setting the budget level can substantially undo the distortions in patterns of compliance. With a good cost signal, the inefficient distribution of compliance within inspected classes is secondary in importance to the fact that inspections will be concentrated on inspection classes with low cost. On the other hand, if the cost signal is very uninformative, it may be more efficient for Congress to restrict the budget and order the agency to ignore cost signals when allocating inspection resources across sectors.

By requiring the agency partially to self-finance from its noncompliance penalties, Congress can mitigate the inefficient distribution of compliance among inspected classes when cost information is imperfect. We have thus illuminated a different source of efficiency gains from rebates than offered in previous literature. Other authors have argued that agencies should be allowed to keep a share of their revenues to reduce moral hazard.

The inefficient distribution of compliance will be exacerbated if levying penalties (prosecution) is costly. Prosecution costs, which vary across regulatory statutes, are 
potentially substantial. Some agencies must conduct a separate hearing for each violator in order to levy a penalty; others do not incur substantial prosecution costs unless a violator challenges a citation and the associated penalty. ${ }^{14}$ Substantial prosecution costs enhance the importance of good information. When cost information is not precise, prosecution costs enhance the importance of rebates.

Without prosecution costs, there would be no social loss due to the uniform standard, given the fine rates are fixed, if the enforcement agency were maximizing social welfare rather than aggregate compliance. Since prosecution costs generally cannot be avoided, uniform standards will lead to inefficiencies once prosecution costs are introduced even if the agency maximizes social wealth.

Though the agency has imperfect cost information, the pattern of compliance can be close to efficient because firms self-select on the basis of compliance cost whether to comply. No analogous mechanism exists to induce self-selection on the basis of benefits. If benefits of compliance vary across sectors, the conclusions are unchanged, so long as the enforcement agency incorporates the benefits of compliance in its enforcement goal and therefore enforces high-benefit sectors more intensively than low-benefit sectors.

Although we have assumed throughout that fine rates are fixed by the enabling legislation that created the enforcement agency, our discussion suggests a partial explanation for why the enforcement agency is not allowed to choose fine rates. By giving agencies the power to set fines, Congress would forfeit the power of the enforcement budget, since full compliance could then be achieved costlessly. For any enforcement budget, the agency maximizing gross benefits could choose penalties sufficiently high to induce full compliance. Congress can prevent this inefficient outcome by reserving the power to set both fine rates and the enforcement budget. In contrast to other explanations in the literature for why optimal fine rates are bounded, this explanation rests on the hierarchical agency problem in which the appropriate committees seek budgetary control over the enforcement agency, and the enforcement agency disciplines firms by inspecting and fining them.

For simplicity, the body of this paper discusses atemporal inspection policies: the probability of inspecting any particular firm does not depend on its history of inspections or compliance. Since there is no opportunity to bring noncompliant firms into compliance as a consequence of the inspection, the only benefits of enforcement with an atemporal policy arise through ex ante deterrence. In the extended version of this paper [8], we show that our main result, that the social loss due to the agency's focus on benefits of compliance may be small, still holds when the enforcement agency can accrue ex post benefits by reinspecting firms to bring them into compliance, and firms know ex ante that reinspection will occur only when it is ex post reasonable for the inspection agency to reinspect.

\section{ACKNOWLEDGMENTS}

We thank Evelyn Brodkin, Edward Gramlich, Jon Harford, and members of the Berkeley and Stanford Industrial Organization Workshops, the University of Michigan Public Finance Seminar, the Carnegie-Mellon Political Economy Workshop, and the Eastern Michigan University Economics Departmental Seminar and two anonymous referees for useful comments. This research was supported by a

\footnotetext{
${ }^{14}$ See "State Civil Penalty Authorities and Policies," Environmental Law Institute, Washington DC, 1985, pp. 43-44 [3]; or "Study of EPA Federal Penalty Practices," Compliance Policy and Planning Branch, Office of Enforcement and Compliance Monitoring, U.S.E.P.A., May 1987 [16].
} 
University of Michigan Rackham Fellowship and Grant, by National Science Foundation, Grant SES-86-10021, and by the Hoover Institution on War, Revolution, and Peace.

\section{REFERENCES}

1. G. Becker, Crime and punishment: An economic approach, J. Polit. Economy 76, 169-217 (1968).

2. J. S. Demski and D. E. M. Sappington, Hierarchical regulatory control, Rand J. Econom. 18, 369-383 (1987).

3. Environmental Law Institute, "State Civil Penalty Authorities and Policies," Washington, DC (1985).

4. D. Evans, The differential effect of regulation across plant size: Comment on Pashigian, J. Law Econom. 29, 187-200 (1986).

5. R. F. Fenno, Jr., The Power of the Purse: Appropriations Politics in Congress, Little, Brown, Boston (1966).

6. C. A. Jones, Models of regulatory enforcement and compliance, mimeo (1982).

7. C. A. Jones, Standard-setting with incomplete enforcement revisited, J. Policy Anal. Management 8, 72-87 (1989).

8. C. A. Jones and S. Scotchmer, “The Social Cost of Uniform Regulatory Standards,” Working Paper \#150, Graduate School of Public Policy, University of California, Berkeley, (1988).

9. A. V. Kneese and B. T. Bower, "Managing Water Quality: Economics, Technology, Institutions," Johns Hopkins, Baltimore (1968).

10. A. V. Kneese and C. T. Schultze, "Pollution, Prices and Public Policy," Brookings Institution, Washington, DC (1975).

11. R. S. Melnick, “The Politics of Partnership," Public Administration Review 45, 653-660 (1985).

12. A. Nichols, "Targeting Economic Incentives for Environmental Protection," MIT Press, Cambridge, MA (1984).

13. A. L. Nichols and R. J. Zeckhauser, "Government comes to the workplace: An assessment of OSHA," Public Interest 49, 39-69 (1977).

14. Research Triangle Institute, "Regulatory Analysis of the Proposed OSHA Standards on Asbestos," for OSHA/DOL (1984).

15. A. Schick, "Congress and Money," Urban Institute, Washington, DC (1980).

16. U.S. Environmental Protection Agency, "Study of EPA Federal Penalty Practices," Compliance Policy and Planning Branch, Office of Enforcement and Compliance Monitoring (1987).

17. U.S.G.A.O., "Use of Spending Authority and Permanent Appropriations is Widespread," Report AFMD-87-44 (1987).

18. U.S. Senate Committee on Government Affairs, "Study on Federal Regulations," Washington, DC (1978). 